\title{
Provocative Tests in Cervical Spine Examination: Historical Basis AND SCIENTIFIC Analyses
}

\author{
Gerard A. Malanga, MD, Phillip Landes, MD, and Scott F. Nadler, DO
}

The majority of the provocative tests described for physical examination of the neck and cervical spine relate to identification of radiculopathy, spinal cord, or brachial plexus pathology. These tests are often performed routinely by many providers with variable methods and interpreted in a variety of ways. Several commonly performed provocative tests include Spurling's Neck Compression Test, Shoulder Abduction (Relief) Test, Neck Distraction Test, L'hermitte's Sign, Hoffmann's Sign and Adson's Test.

This review describes some specialized provocative tests with comprehensive literature review. The goal of this review is to develop standardization in the performance and clinical use of these tests. Each of the tests described in this manuscript apparently originated from the anecdotal observations of experienced, well respected clinicians. However, only few studies have been performed addressing the interexaminer reliability or validity of these tests. The existing literature appears to indicate high specificity, low sensitivity, and good to fair interexaminer reliability for Spurling's Neck Compression Test, the Neck Distraction Test, and The Shoulder Abduction (Relief) Test when performed as described. For Hoffman's Sign, the existing literature does not address interexaminer reliability but appears to indicate fair sensitivity and fair to good specific- ity. For L'hermitte's Sign and Adson's Test, not even tentative statements can be made with regard to interexaminer reliability, sensitivity, and specificity, based on the existing literature.

It is concluded that more research is indicated to understand the clinical utility of all the provocative tests employed in the physical examination of the neck and cervical spine.

Keywords: Provocative tests, cervical spine, Spurling's Neck Compression Test, Shoulder Abduction (Relief) Test, Neck Distraction Test, L'hermitte's Sign, Hoffmann's Sign, Adson's Test, sensitivity, specificity
Many specialized provocative tests have been described for physical examination of the neck and cervical spine. The majority of these relate to identification of radiculopathy, spinal cord pathology, or brachial plexus pathology. These tests are often performed routinely by many providers with variable methods and interpreted in a variety of ways.

The purpose of this review is to describe several commonly performed specialized provocative tests used in examination of the neck and cervical spine regions. For each test, the origin, technique, reliability, validity, and clinical significance are discussed, based on a comprehensive search of the existing literature. The goal is to develop standardization in the performance and clinical use of these tests.

From Sports, Spine and Orthopedic Rehabilitation, Kessler Institute for Rehabilitation, West Orange, New Jersey; and UMDNJ - New Jersey Medical School, Newark, New Jersey. Address Correspondence: Gerard A. Malanga, MD, Kessler Institute for Rehabilitation, West Facility, 1199 Pleasant Valley Way, West Orange, New Jersey 07052. E-mail: gmalanga@pol.net.

There was no outside financial support in preparation of this manuscript.

\section{Spurling's Neck Compression Test}

Spurling and Scoville first described Spurling's Neck Compression Test, also known as, the Foraminal Compression Test, Neck Compression Test, or Quadrant Test, in 1944 as "the most important diagnostic test and one that is almost pathognomonic of a cervical intraspinal lesion" (1). Their observations were based on the presentation of 12 patients with "ruptured cervical discs" verified during surgery in 1943 at Walter Reed Army Hospital. The authors state that during the same period many more of these cases were diagnosed but not verified surgically. They described "the neck compression test" as follows (1).

"Tilting the head and neck toward the painful side may be sufficient to reproduce the characteristic pain and radicular features of the lesion. Pressure on the top of the head in this position may greatly intensify the symptoms. Tilting the head away from the lesion usually gives relief."

Currently the test is described as "performed by extending the neck and rotating the head and then applying downward pressure on the head. The test is considered positive if pain radiates into the limb ipsilateral to the side at which the head is rotated" (2). Some authors advocate performing the components of the test in a staged manner and halting with the onset of radicular symptoms, preferably reproducing the patient's presenting symptoms (3-5). Radicular symptoms are described as pain or paresthesias occurring distant from the neck, in the distribution of a cervical spinal nerve root.

Vikari-Juntura (6) performed a prospective study in 1987 to assess the interexaminer reliability of common tests generally performed in the clinical examination of patients with neck and radicular pain. Two blinded expert examiners, who were trained together in the identical performance of the clinical tests, independently examined fifty-two patients referred for cervical myelography. The neck compression test was performed with each patient in both supine and sitting positions. The patient's neck was passively flexed laterally and slightly rotated ipsilaterally, and the head was then compressed with approximately $7-\mathrm{Kg}$ pressure. A positive test was considered to be the appearance or aggravation of pain, numbness, or paresthesias 
Table 1. Examination maneuvers, original description, reliability analyses and validity testing.

\begin{tabular}{|c|c|c|c|}
\hline Test & Original Description & Reliability Studies & Validity Studies \\
\hline $\begin{array}{l}\text { Spurling's/Neck } \\
\text { Compression Test }\end{array}$ & $\begin{array}{l}\text { Passive lateral flexion, \& compression } \\
\text { of head. Positive test is reproduction of } \\
\text { radicular symptoms distant from neck. }\end{array}$ & $\begin{array}{l}\text { Viikari-Juntura (6) } 1987 \\
\text { Seated position. Kappa }=0.40-0.77 \\
\text { Proportion Specific Agreement }= \\
0.47-0.80\end{array}$ & $\begin{array}{l}\text { Viikari-Juntura et al (7) } 1989 \\
\text { Seated position. Sensitivity: } 40-60 \% \\
\text { Specificity: } 92-100 \%\end{array}$ \\
\hline $\begin{array}{l}\text { Shoulder Abduction } \\
\text { (Relief) Sign }\end{array}$ & $\begin{array}{l}\text { Active abduction of symptomatic arm, } \\
\text { placing patient's hand on head. Positive } \\
\text { test is relief or reduction of ipsilateral } \\
\text { cervical radicular symptoms. }\end{array}$ & $\begin{array}{l}\text { Viikari-Juntura (6) } 1987 \\
\text { Seated position. Kappa }=0.21-0.40 \\
\text { Proportion Specific Agreement } \\
=0.57-0.67\end{array}$ & $\begin{array}{l}\text { Viikari-Juntura et al (7) } 1989 \\
\text { Seated position. Sensitivity: } 43-50 \% \\
\text { Specificity: } 80-100 \%\end{array}$ \\
\hline $\begin{array}{l}\text { Neck Distraction } \\
\text { Test }\end{array}$ & $\begin{array}{l}\text { Examiner grasps patient's head under } \\
\text { occiput and chin and applies axial traction } \\
\text { force. Positive test is relief or reduction of } \\
\text { cervical radicular symptoms. }\end{array}$ & $\begin{array}{l}\text { Viikari-Juntura (6) } 1987 \\
\text { Supine position. } 10-15 \mathrm{Kg} \text { traction } \\
\text { force applied. Kappa }=0.50 \\
\text { Proportion Specific Agreement } \\
=0.71\end{array}$ & $\begin{array}{l}\text { Viikari-Juntura et al (7) } 1989 \\
\text { Supine position. } 10-15 \mathrm{Kg} \text { traction } \\
\text { force applied. Sensitivity: } 40-43 \% \\
\text { Specificity: } 100 \%\end{array}$ \\
\hline L'hermitte's Sign & $\begin{array}{l}\text { Passive anterior cervical flexion. } \\
\text { Positive test is presence of "electric-like } \\
\text { sensations" down spine or extremities. }\end{array}$ & Not reported. & $\begin{array}{l}\text { Uchihara et al (4) } 1994 \\
\text { Sensitivity: ‘... 28\% } \\
\text { Specificity: "high" }\end{array}$ \\
\hline Hoffman's Sign & $\begin{array}{l}\text { Passive snapping flexion of middle finger } \\
\text { distal phalanx. Positive test is flexion- } \\
\text { adduction of ipsilateral thumb and index } \\
\text { finger. }\end{array}$ & Not reported. & $\begin{array}{l}\text { Glaser et al (33) } 2000 \\
\text { Sensitivity: } 58 \% \\
\text { Specificity: } 78 \% \\
\text { Positive Predictive Value: } 62 \% \\
\text { Negative Predictive Value } 75 \%\end{array}$ \\
\hline Adson's Test & $\begin{array}{l}\text { Inspiration, chin elevation, and head } \\
\text { rotation to affected side. Positive test is } \\
\text { alteration or obliteration of radial pulse. }\end{array}$ & Not reported. & Not reported. \\
\hline
\end{tabular}

in the shoulder or upper extremity. For the sitting position, Kappa values ranged 0.40-0.77, which was considered to be "fair to excellent", and the proportion of specific agreement was found to be 0.47 0.80 which was also considered to be "fair to excellent." For the supine position, Kappa values ranged $0.28-0.63$, which was considered to be "poor to good", and the proportion of specific agreement was found to be 0.36-0.67 which was also considered to be "poor to good" (6). The author concluded that this test has good reliability when performed in the sitting position. This is an excellent study and one of the only studies in the literature assessing interexaminer reliability for the Spurling's Neck Compression test and other provocative test maneuvers of the cervical spine. However, the results are analyzed according to the area of symptom radiation (e.g., "right shoulder or upper arm", "right forearm or hand", "left shoulder or upper arm", "left forearm or hand"), instead of classifying the test as positive or negative. This fragments statistical analysis and makes interpretation difficult.

Viikari-Juntura et al (7) published a prospective study in 1989 assessing the validity of Spurling's Neck Compression Test in diagnosing cervical radiculopathy, along with the Axial Manual Traction and Shoulder Abduction tests. Forty-three patients who presented for myelography were interviewed and examined prior to performing the procedure. The Spurling's Neck Compression test was performed with the patient sitting as described in Viikari-Juntura's 1987 study (6). The criterion standard used was myelography combined with neurologic exam findings. Based on the study population's myelographic and clinical findings, statistical analysis was performed only for cervical roots 6-8. Sensitivity ranged $40-60 \%$ and specificity ranged $92-100 \%$. The authors concluded that the test has high specificity but low sensitivity (7). As with the first author's previous study, the results are presented in a manner making interpretation difficult.

In an outstanding review, Wainner and Gill (8) summarize the results of the Viikari-Juntura 1987 (6) and Viikari-Juntura, et al 1989 (7) studies with slightly different findings reported for interexaminer reliability, sensitivity, and specificity than those described above, although the overall conclusions are similar. Tong and Haig (9) reported a sensitivity of $30 \%$ and specificity of $93 \%$ utilizing electrodiagnostic studies as a criterion standard in 224 patients. A study by Sandmark and Nisell (10) reported a specificity of $92 \%$, a sensitivity of $77 \%$, a positive predictive value of $80 \%$ and a negative predictive value of $91 \%$. However, this study used neck pain symptoms as the criterion standard. The neck compression test was considered to be positive if neck pain was produced. This is inconsistent with the original and commonly accepted descriptions of Spurling's sign. Due to these methodological limitations the results should be viewed cautiously. Uchihara et al (11) report a sensitivity of below $28 \%$ and a specificity of $100 \%$. However the criterion standard used was spinal cord deformity on MRI in 65 patients.

In summary, there are few methodologically sound studies, which assess the interexaminer reliability, sensitivity, and specificity of the Spurling's Neck Compression Test. The literature appears to indicate high specificity and low sensitivity. More research is needed to better explore the utility of this commonly used clinical test. 


\section{Shoulder Abduction Test}

Spurling reportedly first alluded to the Shoulder Abduction Test, also described as the Shoulder Abduction Relief Sign, in a monograph published in 1956 (12). He states that "raising the arm above the head sometimes brings relief" of radicular symptoms caused by cervical intervertebral disc pathology. Davidson et al (12) elaborated on this maneuver in 1981, describing their experience with 22 patients who presented with severe cervical radicular pain, sensory, and motor symptoms, initially unresponsive to "outpatient measures," all found to have large lateral extradural lesions on myelography. Fifteen $(68 \%)$ of these patients experienced relief of their radicular symptoms with ipsilateral shoulder abduction. Twelve of 13 patients treated surgically had relief of symptoms, as did the two patients treated nonsurgically. The authors hypothesized that reduced nerve root tension is the most likely cause for symptom relief with shoulder abduction. They concluded that the Shoulder Abduction Relief Sign is indicative of nerve root compression and predictive of excellent response to surgical treatment (12).

The Shoulder Abduction Relief Test is currently described as active or passive abduction of the ipsilateral shoulder so that the hand rests on top of the head, with the patient either sitting or supine. Relief or reduction of ipsilateral cervical radicular symptoms is indicative of a positive test (4). In a brief report of three cases, Beatty et al (13) described this sign to be indicative of radiculopathy secondary to cervical disc pathology but not from cervical spondylosis. Ellenberg and Honet described the Shoulder Abduction Relief Sign as helpful in distinguishing cervical radiculopathy from shoulder pathology, when present. In their experience the sign is "frequently not present" with cervical radiculopathy.

Viikari-Juntura (6) prospectively studied the interexaminer reliability of the Shoulder Abduction Relief Test in 31 patients as described in section I above. The test was performed in the seated position in the presence of radicular pain, paresthesia, or numbness. The patient was instructed to "lift" his hand above the head. The decrease or disappearance of radicular symptoms indicated a positive test. Kappa scores were poor to fair and ranged from 0.21-0.40. The proportion of specific agreement was fair to good, ranging 0.57 to 0.67 . Overall, the test's reliability was described as "fair" (6).

Viikari-Juntura et al (7) as described in section I above, investigated the validity of the Shoulder Abduction relief Test in 1989. The test was performed as described in the 1987 interexaminer reliability study on 22 of the patients. Sensitivity ranged from $43 \%$ to $50 \%$ and specificity ranged from $80 \%$ to $100 \%$. The authors concluded that the test is highly specific for cervical radiculopathy with low sensitivity.

The literature seems to indicate high specificity with low sensitivity for the Shoulder Abduction Relief Test. However the only available prospective study examined a small number of subjects for this test. The only investigation of interexaminer reliability concluded the test to be "fair". Interestingly, incorporation of the abduction maneuver into a nonsurgical treatment program is reported as beneficial for patients with a positive test (14).

\section{Neck Distraction Test}

The Neck Distraction Test is also described as the Axial Manual Traction Test. The origin of this maneuver is uncertain although it is well described in the current literature.

"To perform the distraction test, the examiner places one hand under the patient's chin and the other hand around the occiput, then slowly lifts the patient's head. The test is classified as positive if the pain is relieved or decreased when the head is lifted or distracted, indicating pressure on nerve roots that has been relieved" (4).

This test is commonly performed in the supine position in the presence of radicular symptoms. A positive test is indicated by relief or lessening of the radicular symptoms $(3,6-8)$. This is thought to indicate cervical radiculopathy caused by discogenic pathology.

Viikari-Juntura (6) concluded that the interexaminer reliability of the Neck Distraction test is "good". In his prospective study described in section I, a traction force of 10 to $15 \mathrm{Kg}$ was applied to $29 \mathrm{sub}$ jects. Kappa values were 0.50 and the proportion of specific agreement was 0.71 . Using the same examination technique, Viikari-Juntura et al (7) reported a specificity of $100 \%$ and a sensitivity of $40-43 \%$. The authors conclude that the Axial Manual Traction test has low sensitivity but is highly specific for radicular pain, and for neurologic and radiologic signs of radiculopathy from cervical disc disease. No other studies of interexaminer reliability or validity are reported in the literature.

\section{L'hermitte's Sign}

What is now referred to as L'hermitte's Sign, was first described on December 20, 1917 by Marie and Chatelin $(15,16)$. They reported the description of "transient 'pins and needles' sensations traveling the spine and limbs on flexion of the head" in some patients with head injuries at the meeting of the Centers of Military Neurology in Paris $(15,16)$. They believed that these symptoms were caused by positional pressure on cervical nerve roots. Less than one month later, Babinski and Dubois (17) described a patient with a Brown-Sequard syndrome who reported sensations of 'electric discharge' upon flexing the head, sneezing, or coughing. They attributed the symptom to the presence of an intramedullary lesion. L'hermitte first wrote on this topic in 1920 (18) when he further elaborated on the symptom's origin in patients with "concussion of the spinal cord." He attributed these symptoms to posterior and lateral column pathology in the cervical spinal cord $(15,18)$. L'hermitte reported the findings to the Neurological Society of Paris in 1924 (15). This was entitled "Pain in the form of an Electric Discharge Character Following Head Flexion in Multiple Sclerosis." The authors attributed the "electric discharge" symptoms to demyelination of cervical spinal cord segments and believed this to be an early finding in multiple sclerosis. L'hermitte wrote further about this finding in multiple sclerosis and in other conditions of cervical spinal cord pathology throughout his career (15).

L'hermitte's Sign is currently described and performed in a variety of ways. It is most commonly described as passive anterior cervical flexion to end range with the patient seated. A positive test is indicated by the presence of an "electric-like" sensation down the spine or in the extremities. This is described to occur with cervical spinal cord pathology from a wide variety of conditions, including Multiple Sclerosis, spinal cord tumors, cervical spondylosis, and radiation myelitis $(2,3,19)$. The test is also currently described as performed in the following manner although different from the de- 
scriptions above (4).

"The patient is in the long leg sitting position on the examining table. The examiner passively flexes the patient's head and one hip simultaneously, with the leg kept straight. A positive test occurs if there is a sharp pain down the spine and into the upper or lower limbs; it indicates dural or meningeal irritation in the spine or possible cervical myelopathy."

No reports investigating the interexaminer reliability of L'hermitte's Sign could be found in the literature. There are two studies describing the validity of L'hermitte's Sign, although both have methodologic flaws as described in section I above. Sandmark and Nissell (10) reported $27 \%$ sensitivity, $90 \%$ specificity, $55 \%$ positive predictive value, and $75 \%$ negative predictive value for the "Active Flexion and Extension Test." which partly resembles L'hermitte's Test. Uchihara et al (11) reported high sensitivity and less than $28 \%$ sensitivity although exact percentages are difficult to discern.

L'hermitte's Sign which was originally described anecdotally, continues to be based on anecdotal observation.

\section{Hoffmann's Sign}

The origin of what is now described as Hoffmann's sign remained controversial through the late 1930's until a medical student named Otto Bendheim found a reference to the reflex in a paper written by Hans Curschmann on uremia in 1911 $(20,21)$. Several prominent Neurologists had previously been unable to identify the sign's origin. In 1916, Keyser (22) published a paper suggesting the name "Hoffmann's sign" be dropped for "digital reflex" after an extensive search failed to identify the origin of the reflex. Likewise, in 1933, Fay and Gotten published a comprehensive paper on the subject but failed to identify the origin of the reflex (20).

The sign is attributed to Johann Hoffmann, professor of Neurology at Heidelberg, Germany in the late nineteenth and early twentieth centuries, a pupil of Erb. Hoffmann was reported to demonstrate the sign routinely in lectures and clinics, although he did not discuss it through publication $(20,23)$. Hoffmann's assistant, Hans Curschmann, who became professor of Medicine at the University of Rostock, Germany, described the reflex in the literature in 1911, and named it Hoffmann's Sign $(21,23)$. In 1913, a Neurol- ogist in Hamburg, E. Tromner, independently and without knowledge of Curschmann's paper, described the reflex as well $(20,21,24,25)$. In response to an inquiry, Dr. Curschmann (21) later wrote:

"The finger phenomenon mentioned by me originates from Johann Hoffmann, Professor of Neurology at Heidelberg (died 1919). I learned it while his pupil and assistant from 1901 to 1904 . He demonstrated it in his classes and clinics as a sign of hyperreflexia of the upper extremity. So far as I know he never published it"

Hoffmann's Sign was originally described as follows (21):

"The test is performed by supporting the patient's hand so that it is completely relaxed and the fingers partially flexed. The middle finger is firmly grasped, partially extended, and the nail snapped by the examiner's thumbnail. The snapping should be done with considerable force, even to the point of causing pain. The sign is present if quick flexion of both the thumb and index finger results. Fingernails other than the middle one are sometimes selected for the snapping. The sign is said to be incomplete if only the thumb or only the fingers move."

There continues to be disagreement as to whether the sign is present if only the thumb flexes, as advocated by Schneck, Madonick and others $(26,27)$. Keyser (22) described the test to be positive "if definite flexion of either the thumb or one or more fingers results."

Reportedly, Jakobson also described a similar sign, independently and after Hoffmann (20). This was published in 1908, before Curschmann's paper. Jakobson tapped the distal radius instead of snapping the nail (20).

The clinical significance of Hoffmann's Sign has been long disputed $(21,26,27,28)$. In a comprehensive review, Madonick (27) described three general views. One is that the Hoffmann's sign is a "pathologic sign, indicating pyramidal tract involvement." This view was held by Keyser, Fay and Gotten, Fulton and Viets, Perelman, Echols, Kastein, Lange, Madonick, and Purves-Stewart (27). A second view is that the Hoffmann sign "indicates pyramidal-tract involvement but that, owing to its frequent presence in other conditions, its clini- cal value is doubtful." This is the position supported by Schneck, Pitfield, Dana, Nielsen, and Monrad -Krohn (27). Finally, many "do not consider the Hoffmann sign as pathologic or of any clinical value." This is the reported general view of Cooper, Wartenberg, Brain, Grinker and Bucy, and Alpers (27). They believed that this sign indicated a "state of increased muscle tone" due to a variety of factors (27). It appears that the second and third views regarding the significance of Hoffmann's Sign as described by Madonick are actually similar. Pitfield (28) observed the sign to be inconsistent in individual patients and to frequently be present in patients with cardiovascular disease. He devised a scale classifying the degree in which the response follows the nail snapping into four groups, "plus 1" to "plus 4". $\mathrm{He}$ also described a maneuver thru which "in many the reflex may be reinforced if present or made to appear if absent."

"The upper arm is encircled by the cuff of a blood pressure apparatus; this is blown to $300 \mathrm{~mm}$; if then the prone hand is examined by snapping the nail an apparently absent reflex will become positive and faint ones will be exalted to a plus three or four. After releasing the pressure and removing the cuff, it sometimes can be noted that a condition of exultation will persist for some minutes, the reflex being more active than it was before compression."

Denno and Meadows (29) described "the dynamic Hoffman's sign" as a modification of Hoffmann's sign to assist in the diagnosis of early spondylotic cervical myelopathy. This is performed by "multiple active full flexion to extension of the neck" prior to performing the Hoffman's sign maneuver as originally described.

There are several studies in the literature investigating the incidence of Hoffmann's sign. In 1933, Fay and Gotten reported Hoffmann's signs in 21 of 393 "supposedly healthy" college students with Babinski signs in 14. Only eight of the 21 students with Hoffmann's signs had no history of brain injury or other central nervous system pathology ("sunstroke", epilepsy, meningitis). These authors also noted Hoffmann's signs in two of 285 patients hospitalized in the Philadelphia General Hospital for non-neurologic conditions. One of these two patients with Hoffmann's signs also had a Babinski sign $(27,28)$. In contrast, of 339 patients 
hospitalized for "organic nervous disease," 139 had Hoffmann's signs and 140 had Babinski signs (28). Fay and Gotten concluded that the Hoffmann sign indicates pyramidal tract pathology, and that the sign may be present in patients without a Babinski sign if "the lesion involves the areas or fibers concerned in motor function of the upper extremity" (27). Echols (21) examined 2,017 students at the University of Michigan and observed a Hoffmann's sign in 159 using the lenient criteria of "the slightest suggestion of flexion of the index finger, the thumb or both." After 4 months 153 were re-examined and 32 patients no longer demonstrated the sign, 68 had an "incomplete Hoffmann's sign" with flexion of only one or more fingers, and 53 had a "true Hoffmann's sign" with flexion of both the thumb and index fingers in response to snapping the middle finger, the ring finger, or both. Of the 53 students with "true Hoffmann's signs," only 33 had no history of prior head injury or other central nervous system pathology $(21,27)$. The incidence of a "true Hoffmann's sign" was $2.62 \%$, the incidence of an "incomplete Hoffmann's sign" was $3.37 \%$, and the incidence of an unexplained “true Hoffmann's sign" was $1.63 \%$ in this study, compared with a $2 \%$ incidence of unexplained Hoffmann's signs in Fay and Gotten's study. Echols (21) concluded that, "the (true) Hoffmann sign almost always indicates a disturbance of the pyramidal pathway" and "the significance of an incomplete Hoffmann's sign is still unsettled." It should be noted that despite the low incidence, $38 \%$ of the patients with Hoffmann's signs in Fay and Gotten's study (8/21) and $62 \%$ of the patients with true Hoffman's signs in Echols' study (33/53) were unexplained.

In 1946, Schneck (26) published a preliminary report of a "2.5-3\%" incidence of Hoffmann's sign in more than 2,500 subjects in the military. The sign was unilateral in "almost" 50\%. A Hoffmann's sign was defined as "flexion of the thumb on passive flexion, by the examiner, of the distal portion of the patient's middle finger, with sudden release...flicking..." Reportedly, "in the majority of subjects in this study either no history of neurologic disease was elicited or no pathological finding on the neurological examination was found."

Perelman (27) reported a $2 \%$ incidence of Hoffmann's signs in 694 medical students and registrants at a rail- way technical school. He also reported a $1.4 \%$ incidence of Hoffmann's sign in a group of 208 patients with "medical, surgical, and peripheral disorders of the autonomic nervous system." Perelman believed that a Hoffmann's sign is clinically significant for pathology to the corticospinal pathway rostral to the seventh cervical segment.

In 1952, Madonick (27) published a comprehensive study of 2,500 patients with non-neurologic disease admitted to the Morrisania City Hospital, and included an extensive literature review of Hoffmann's sign. The sample was reported to be statistically valid with regard to age, but somewhat skewed with regard to gender $(68 \%$ females $)$, and race $(11.6 \% \mathrm{Ne}-$ groes). A Hoffmann's sign was considered positive if flexion of the thumb occurred. The overall incidence of Hoffmann's sign was found to be $2.08 \%$ (52/ 2500). The sign was more frequent with advancing age. The incidence was $0.7 \%$ in those $0-19,1.2 \%$ in those $20-39,3.4 \%$ in those $40-59$, and $4 \%$ in those over 60 years of age (27). Savitsky and Madonick (30) observed the same trend for the Babinski sign with an overall $4.3 \%$ incidence of the Babinski sign in the sample. The incidence of Hoffman's sign was $5.8 \%$ in the 195 patients with hypertension, and 0.3 $\%$ in the 300 "psychoneurotic" patients. The sign was unilateral in $60 \%$ of the patients and $30 \%$ of the patients with Hoffmann's signs had other abnormal findings on exam. Madonick (27) concluded that, "the Hoffmann sign is a sign of pyramidal tract involvement." However, he also stated "it is difficult to determine whether the Hoffmann sign is due to functional disturbance of the pyramidal tract or whether it indicates only a state of increased muscle tone, as propounded by Wartenberg."

Sung and Wang (31), in 2001, prospectively evaluated 16 asymptomatic patients with a positive Hoffmann's reflex using cervical radiographs and magnetic resonance imaging (MRI). Fourteen of $16(87.5 \%)$ cervical spine $x$-rays were abnormal with spondylosis and all 16 MRI's were interpreted as abnormal with spondylosis and cord compression in 15. The authors concluded that, "the presence of a positive Hoffman's reflex was found to be highly associated with the presence of a cervical spine lesion causing neural compression." Imaging studies or further evaluation is not recommended, as the cohort studied remained asymptomatic, with continued yearly follow-up (31). This study is limited by a small number of subjects and by the lack of a control group, although reference is made to other studies regarding the incidence of positive radiographic abnormalities in the cervical spines of asymptomatic patients. In addition the authors did not evaluate for possible brain pathology, which might be responsible for the presence of a positive Hoffman's sign.

Clinical Neurology, edited by Joynt and Griggs (32), described the Hoffmann's sign as a variation of the finger flexor reflex, indicating muscle stretch reflex hyperactivity, when present. It is described to be suggestive of pyramidal tract pathology rostral to the sixth cervical segment, especially if complete, unilateral, and associated with other neurologic abnormalities. However, its presence is stated to not always be indicative of pathology. It is described in association with increased muscle tone and generalized reflex hyperactivity to include "tension states." Further, "an incomplete Hoffman sign is encountered fairly frequently in healthy persons."

There are no known studies assessing the interexaminer reliability of the Hoffman's sign. Glaser et al (33), reported $58 \%$ sensitivity, $78 \%$ specificity, $62 \%$ positive predictive value, and $75 \%$ negative predictive value in a study of 124 patients presenting with cervical complaints. Imaging of the cervical spinal canal for evidence of cord compression with CT or MRI was used as the criterion standard. When only results of the patients with cervical spine MRI's were evaluated using blinded neuroradiologists, the findings were different. For these patients, the test had 33\% sensitivity, 59\% specificity, $26 \%$ positive predictive value, and $67 \%$ negative predictive value. Authors concluded that the Hoffman's sign, "without other clinical findings" is not a reliable test to screen for cervical spinal cord compression. This retrospective study is useful despite its methodological flaws.

In summary, the significance of the Hoffman's sign remains disputed in the literature. It appears to be indicative of possible pyramidal tract pathology. However, it may be present with generalized conditions of increased muscular tone in otherwise asymptomatic individuals with or without recognized underlying pathology. The overall incidence in the population appears to be $2-3 \%$ with differenc- 
es in the literature related to variability in study samples and in the precise definition. The incidence of an "unexplained" Hoffmann's sign in the population, present without history or exam findings of occult neurological pathology, is reported to be $1.5-2 \%$. The validity has not been well studied although poor to fair sensitivity and fair to good specificity are reported. The interexaminer reliability has not been reported. Further studies exploring the validity and interexaminer reliability of Hoffmann's sign are indicated.

\section{Adson's Test}

In 1927, Adson and Coffey (34) described a technique to assess for evidence of circulatory symptoms caused by the presence of a cervical rib. "Diminution in volume of the radial pulse is common; the pulse can be decreased or obliterated by having the patient elevate the chin or rotate the head to the affected side while inspiring air. This was felt to be due to "constriction of the subclavian artery or vein, obstruction of the radial and ulnar arteries by emboli at the site of constriction, or possibly by disturbance of the sympathetic innervation." They believed that this evidence of circulatory disturbance warranted consideration for surgical resection of the cervical rib. However, later in the same article, in discussing the cause of the various symptoms in patients with cervical ribs, Adson and Coffey (34) described the test somewhat differently.

"Clinically, we were able to demonstrate the influence of the scalenus anticus muscle by having the patient elevate the chin and extend the neck or rotate the head to the affected side while taking a deep inspiration: this produces paresthesia over the distribution of the brachial plexus and, frequently, obliteration of the pulse at the wrist on the affected side."

Adson (35) further elaborated on this test and called it "The Vascular Test" in an article published after his death in 1951.

"The test consists of having the patient take a long breath, elevate his chin and turn it to the affected side. This is done as the patient is seated upright, with his arms resting on his knees. An alteration or obliteration of the radial pulse or change in blood pressure is a pathognomonic sign of the presence of a cervical rib or the scalenus anticus syndrome."

Adson (35) stated in this article that if the Vascular Test is positive, scalenotomy is indicated. He believed the test to indicate subclavian artery compression. "If the subclavian artery has been compressed, there is a strong probability that the brachial plexus also is irritated or compressed whenever the scalenus anticus muscle is placed on tension, since the artery is being displaced posteriorly against trunks of the plexus." He attributed the vascular and neurologic symptoms to a hypertrophied scalene anticus muscle often but not always in the presence of a cervical rib. He further stated, "Little has been accomplished by scalenotomy unless the Vascular Test gives a positive result." His conclusions were based on personal observation of operative findings. These conclusions were further supported by his retrospective review of all 169 patients treated by the neurosurgical staff at the Mayo Clinic from January 1925 to August 1951 with scalenotomy. Of these patients, 75 had scalenotomy without resection of cervical ribs, 30 had scalenotomy and partial rib resection, and 64 had scalenotomy performed in the absence of cervical ribs. The operative findings revealed, "In all cases in which the result of the vascular test was positive, the scalene anticus muscle produced a compression of the subclavian artery on each inspiration." Eightyone to ninety percent of all patients had complete relief or "great improvement" in symptoms following surgery.

Adson's test is currently described in the following manner (4):

"The patient's head is rotated to face the tested shoulder. The patient then extends the head while the examiner laterally rotates and extends the patient's shoulder. The examiner locates the radial pulse, and the patient is instructed to take a deep breath and hold it. A disappearance of the pulse is indicative of a positive test."

The interexaminer reliability and validity of Adson's test have not been further reported in the literature.

\section{Conclusion}

The majority of the specialized provocative tests commonly used in examination of the cervical spine and related neck structures are purported to assist in identification of radiculopathy, spinal cord pathology, or brachial plexus pathology. Each of the tests described in this article apparently originated from the anecdotal observations of experienced, well respected clinicians. Few studies have been performed addressing the interexaminer reliability or validity of these tests. Of the studies performed, most were not methodologically sound or had other limitations. The existing literature appears to indicate high specificity, low sensitivity, and good to fair interexaminer reliability for Spurling's Neck Compression test, the Neck Distraction test, and the Shoulder Abduction (Relief) test when performed as described. For Hoffmann's Sign, the existing literature does not address interexaminer reliability but appears to indicate fair sensitivity and fair to good specificity. For L'hermitte's Sign and Adson's test, not even tentative statements can be made with regard to interexaminer reliability, sensitivity, and specificity, based on the existing literature. It should be emphasized that more research is indicated to understand the clinical utility of all of these tests. As Wainner and Gill (8) state with regard to cervical radiculopathy, many investigators believe that "Given the paucity of evidence, the true value of the clinical examination... is unknown at this time."

Common consensus appears to be that none of the specialized provocative tests used in examination of the cervical spine has the reliability, sensitivity, and specificity to determine the presence or absence of specific cervical pathology, in isolation. They appear to have greatest clinical utility in the context of the patient's clinical history and other exam findings. As Schneck (26) stated regarding Hoffmann's Sign, "the...sign as a positive indication of organic pathology would seem to bear greater significance when accompanied by a suggestive history or by other pathological signs or symptoms." 
Author Affiliation

Gerard A. Malanga, MD

Kessler Institute for Rehabilitation,

West Facility, 1199 Pleasant Valley

Way, West Orange, New Jersey 07052,

(973) 736-9090, fax (973) 243-6861

or E-mail: gmalanga@pol.net

Phillip Landes, MD

Kessler Institute for Rehabilitation,

West Facility, 1199 Pleasant Val-

ley Way, West Orange, New Jersey

07052, (973) 736-9090, fax (973)

243-6861

Scott F. Nadler, DO

UMDNJ - New Jersey Medical School, Doctors Office Center, Newark, New Jersey

\section{RefERENCES}

1. Spurling RG, Scoville WB. Lateral rupture of the cervical intervertebral discs: a common cause of shoulder and arm pain. Surg Gynecol Obstet 1944; 78:350-358.

2. Malanga GA. The diagnosis and treatment of cervical radiculopathy. Med Sci Sports Exerc 1997; 29:S236-S245.

3. Ellenberg M, Honet JC. Clinical pearls in cervical radiculopathy. Phys Med Rehabil Clin North Am 1996; 7:487-508.

4. Magee DJ., Cervical Spine. In: Orthopedic Physical Assessment. 3rd ed. WB Saunders Company; Philadelphia, 1997.

5. Bradley JP, Tibone JE, Watkins RG. History, physical examination, and diagnostic tests for neck and upper extremity problems. In Watkins RG (ed.) The Spine in Sports. Mosby-Year Book Inc, St Louis, 1996.

6. Viikari-Juntura E. Interexaminer reliability of observations in physical examinations of the neck. Phys Ther 1987; 67:15261532.

7. Viikari-Juntura E, Porras M, Laasonen EM. Validity of clinical tests in the diagnosis of root compression in cervical disease. Spine 1989; 14:253-257.
8. Wainner RS, Gill H. Diagnosis and nonoperative management of cervical radiculopathy. I Orthoped Sports Phys Ther 2000; 30:728-744.

9. Tong HC, Haig AJ. Spurling's test and cervical radiculopathy. Proceedings of the American Academy of Physical Medicine and Rehabilitation Annual Assembly, San Francisco, Nov 4, 2000.

10. Sandmark H, Nisell R. Validity of five common manual neck pain provoking tests. Scand J Rehab Med 1995; 27:131-136.

11. Uchihara T, Furukawa T, Tsukagoshi $\mathrm{H}$. Compression of brachial plexus as a diagnostic test of cervical cord lesion. Spine 1994; 19:2170-2173.

12. Davidson RI, Dunn EJ, Metzmaker JN. The shoulder abduction relief test in the diagnosis of Radicular pain in cervical extradural compressive monoradiculopathies. Spine 1981; 6:441-446.

13. Beatty RM, Fowler FD, Hanson EJ. The abducted arm as a sign of ruptured cervical disc. Neurosurgery 1987; 21:731-732.

14. Fast A, Parikh S, Marin EL. The shoulder abduction relief sign in cervical radiculopathy. Arch Phys Med Rehabil 1989; 70: 402-403.

15. Gutrecht JA. Lhermitte's sign: from observation to eponym. Arch Neurol 1989; 46: 557-558.

16. Marie P, Chatelin C. Sur certains symtomes vraisemblablement d'orogine radiculaire chez les blesses du crane. Rev Neurol 1917; 31:336.

17. Babinski J, Dubois R. Douleurs a forme de decharge elictrique, consecutives aux traumatismes de la nuque. Presse Med 1918; 26:64.

18. Lhermitte J. Les formes douloureuses de commotion de la moelle epiniere. Rev Neurol 1920; 36-257-262.

19. Ellenberg MR, Monet JC, Treanor WJ. Cervical radiculopathy. Arch Phys Med Rehabil 1994; 75:342-352.

20. Bendheim OL. On the history of Hoffmann's Sign. Bull Inst Hist Med 1937; 5: 684-685.

21. Echols DH. The Hoffmann Sign: its in- cidence in university students. J Nerv \& Ment Dis1936; 84:427-431.

22. Keyser TS. Hoffmann's Sign or the "Digital Reflex." J Nerv \& Ment Dis 1916; 44:51-62.

23. Curschmann $\mathrm{H}$. Uber die diagnostiche bedeutung des Babinskischen phanomens im prauramischen zustand. Munch Med Wchnschr 1911; 58:2054-2057.

24. Tromner E. Ueber sehnen-respective muskelreflexe und die merkmale ihrer schwachung und steigerung. Berl Klin Wchnschr 1913; 50:1712-1715.

25. Cooper MJ. Mechanical factors governing the Tromner Reflex. Arch Neurol \& Psychiat 1933; 30:166-169.

26. Schneck JM. The unilateral Hoffmann reflex. J Nerv Ment Dis 1946; 104:597-598.

27. Madonick MJ. Statistical control studies in neurology: III. The Hoffmann Sign. Arch Neurol \& Psychiat 1952; 68:109-115.

28. Pitfield RL. The Hoffmann Reflex - a simple way of reinforcing it and other reflexes. I Nerv \& Ment Dis 1929; 69:252-258.

29. Denno JJ, Meadows GR. Early diagnosis of cervical spondylotic myelopathy: a useful clinical sign. Spine 1991; 16:1353-1355.

30. Savitsky N, Madonick MJ. Statistical control studies in neurology: I. The Babinski sign. Arch Neurol \& Psychiat 1943; 49:272276.

31. Sung RD, Wang JC. Correlation between a positive Hoffman's reflex and cervical pathology in asymptomatic individuals. Spine 2001; 26:67-70.

32. Joynt RJ, Griggs RC. Clinical Neurology Vol. 1. Lippincott, Williams and Wilkins; Philadelphia, 1998: 61-62.

33. Glaser JA, Curie JK, Bailey KL et al. Cervical spinal cord compression and the Hoffman sign. lowa Orthop / 2001; 21:49-52.

34. Adson AW, Coffey JR. Cervical rib: A method of anterior approach for relief of symptoms by division of the scalenus anticus. Ann Surg 1927; 85:839-857.

35. Adson AW. Cervical ribs: symptoms, differential diagnosis, and indications for section of the insertion of the scalenus anticus muscle. J Internat Coll Surg 1951; 16: 546-559. 
